\title{
Catástrofe conversada
}

\section{Constança Carvalho Homem}

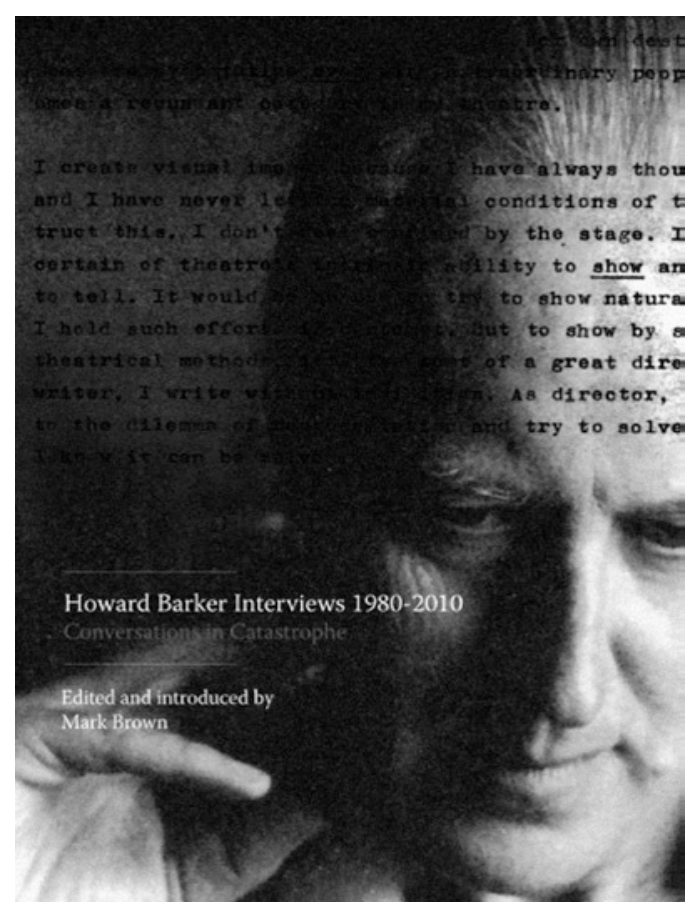

Uma entrevista pode, como, num certo sentido, talvez só uma carta possa, revelar uma imagem mais inteira e matizada de um autor do que a que se deduz da respectiva obra. Com o justo interlocutor, a entrevista pode dar a ver a voz que defende um programa, na medida em que se escuda, se entusiasma, declara ambições e mágoas, na medida em que até um raciocínio obstinado trai a sua humana natureza. Parece ter sido este o mote para que Mark Brown, actualmente crítico do Sunday Herald e membro do Comité Executivo da Associação Internacional de Críticos de Teatro (AICT-IATC), tenha querido congregar um ciclo de entrevistas a Howard Barker, dramaturgo de quem é declarado apreciador.

0 volume compilado por Mark Brown - Howard Barker Interviews 1980-2010: Conversations in Catastrophe, saído em Bristol \& Chicago, em 2011, com a chancela Intellect -, reúne, em 214 páginas, um conjunto de dezassete entrevistas, quer anteriormente dispersas por periódicos da especialidade, teses e antologias de ensaios, quer nunca antes editadas. 0 elenco de entrevistadores é váriado, mas inclui alguns dos mais reconhecidos mediadores da obra de Barker. Digo mediadores porque parte dos cúmplices que o dramaturgo encontrou em círculos académicos, e que aqui são contemplados, tem vindo a dedicar-se não apenas a uma produção ensaística que incide nas relações que a sua obra dramática e teórica estabelece entre si e com o cânone, mas ao confronto directo com as

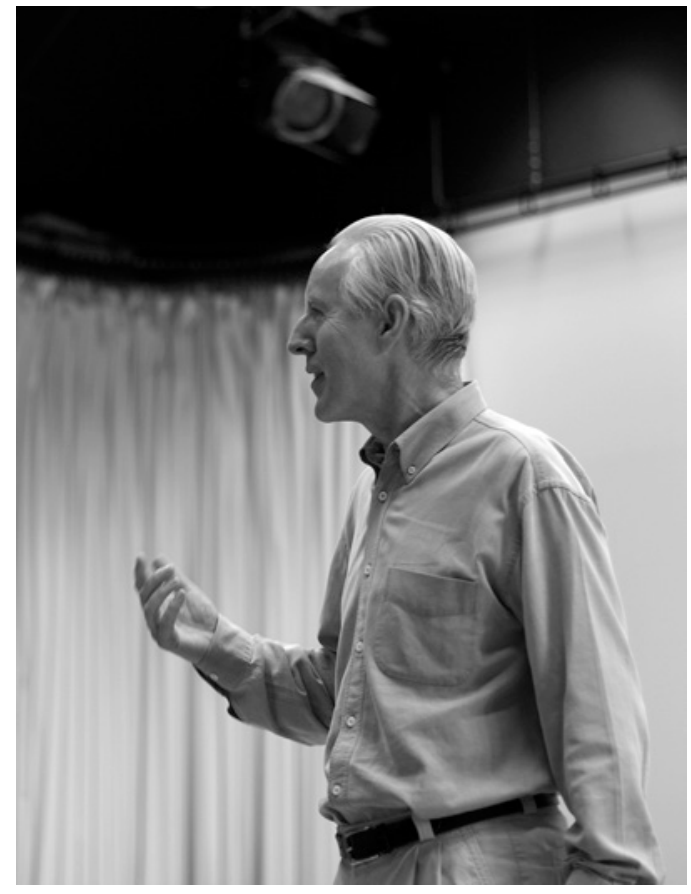

Capa do livro.

Howard Barker,

2009,

fot. Constança Carvalho

Homem.

contingências de tradução e concepção decorrentes das suas peças. Penso em David lan Rabey e Charles Lamb, que acumulam contribuições neste volume, bem como em Elisabeth Angel-Perez, Vanasay Khamphommala ou Elizabeth Sakellaridou. Estamos globalmente perante um corpo de entrevistas conduzidas por

leitores/espectadores/praticantes preferenciais, e que albergam questões relativas à execução e recepção da obra, deixando sempre margem à afirmação da sua militante e específica condição literária. Faz-se, por um lado, a tentativa de delimitar a obra de Barker face, por exemplo, a

Stanislavski, Brecht ou Tchekov, e de dilucidar que afinidades poderá manter com a matriz shakesperiana, o teatro jacobita e a dramaturgia contemporânea; concomitantemente, discute-se o "sacrifício" do actor, assim como a função do objecto, da nudez e do excesso de linguagem postos em cena.

Para o leitor que desconheça a obra de Barker, este volume tem o mérito óbvio de permitir a aproximação às suas teses por meio de um registo dialógico, descontraído e menos elíptico que o de Arguments for a Theatre (1997) ou Death, The One and The Art of Theatre (2005), mas que com ambos mantém vínculos intimos, pode dizer-se até de ordem intertextual. 0 léxico que é característico do Teatro da Catástrofe - os títulos temáticos recortam desde logo as noções de "possibilidade", "morte", "crise", "êxtase", "poesia" e "obscuridade", centralissimas preocupações da
$>$ 
sua prática - recebe aqui repetida confirmação. Por outro lado, e este é um benefício para qualquer leitor, o arranjo cronológico do livro, bem como o facto de que as entrevistas que o inauguram e encerram são de conta-corrente (dos dez primeiros anos e da totalidade da sua carreira, respectivamente), permitem uma visão panorâmica em que se consolidam a renúncia a uma dramaturgia de molde realista e didáctico e a eleição da tragédia enquanto fenómeno cultural pré-purgativo, desprovido de "valor social", veículo para a superação, a especulação moral e a reverberação da língua. É neste contexto que surgem afirmações como "a narrativa tornou-se claramente parte do sistema" (p. 45) ou ainda "a lógica pode ser intrínseca à linguagem, mas não é intrínseca à poesia, que é o método da minha escrita" (p. 50), em perfeita consonância com o argumentário previamente vindo a público.

Sustenta este panorama a profusa exemplificação com textos publicados ou produzidos em ocasião contígua à da entrevista, sendo também frequente a ilustração com fotografias de cena. 0 pano de fundo para o percurso proposto é o agudizar da percepção de "hostilidade crítica" em que se funda o voluntário exílio de Barker (percepção subscrita, aliás, pelo editor) e que produzirá declarações como a seguinte: "Os críticos policiam a cultura, obviamente. 0 facto de a actual geração de polícias ser liberal, humanista dita progressiva e por ai fora não significa que não sejam sempre polícias, permanentemente a excluir as obras que possam infectar o plácido jardim do engenho e da civilidade" (p. 94). É porventura essa percepção que igualmente inflama certa auctoritas subjacente a asserções como as seguidamente transcritas, que creio lidas com bonomia mesmo por Barkeristas convictos: "Aristóteles - que, no final de contas, é apenas um crítico, pensemos nele sob essa perspectiva" (p. 114); "Shakespeare nunca inventou uma história na vida; desse ponto de vista, sou-lhe muitíssimo superior" (p. 167); "sou um grande admirador de Adorno - um Marxista que também era um burguês, $e$ esses são os mais interessantes" (p. 118).

Nem sempre Barker nos surge tão ácido e categórico. Alguns dos apontamentos autobiográficos que faz indicam generosamente as eventuais origens de certas recorrências na obra. Ao Theatre Quarterly, Barker recordará: "Mas nós - só alguns, vistos com prudência pelos professores e pelo grosso da escola - costumávamos improvisar uma série satírica/surrealista à hora do almoço, na parte de trás de um camião do exército abandonado. Interpretávamos personagens que desprezávamos, como o Dr. Barnardo,
Ernest Shackleton, Kennedy, Cristo e James Bond. Também havia figuras diabólicas, como Crippen e Hitler. Mas nunca pensámos estar a fazer teatro. [...] Suponho que o espírito daquilo que faziamos tenha sido influenciado pela ascensão do boom satírico" (pp. 19-20). Este relato não pode deixar de articular-se com o que, ainda na mesma entrevista, declara ser o seu combate para não produzir apenas personagens satíricas e momentos satíricos, que factualmente marcam presença na sua produção inicial. Por outro lado, a questão da proclamada identidade europeia de Barker remonta, de acordo com o que declara a Aleks Sierz (p. 118), aos seus sete ou oito anos, momento em que começa a pensar em si como vienense. Explicará entretanto, em várias entrevistas, que o ser "europeu" implica a assimilação de diversas e conflituais influências. Respigando a informação, é possivel fazer uma lista que inclua Céline, Joseph Roth, Thomas Mann, Kafka, Rembrandt Bosch, Goya, Rothko, Buñuel, Pasolini, Tarkovsky, Rilke, Apolinaire e George Oppen, entre outros, e que ostensivamente exclui qualquer dramaturgo. Talvez este conjunto ajude a perceber o esmero formal, a torrencialidade e o peso da imagem na sua dramaturgia.

Direi finalmente que a fluência do pensamento artístico de Barker, que Brown destaca na introdução, é porventura a melhor garantia de uma leitura vibrante. E será, creio, motivo para que este livro suscite a citação tanto quanto qualquer um dos que Barker assinou. Concluo, pois, com uma dessas inequívocas sentenças a que reconheço o poder da autonomia:

\footnotetext{
Neste miasma generalizado do entretenimento, se o espírito humano sequer existe em bolsas isoladas de resistência, há-de identificar-se com uma demanda do problemático, por oposição ao celebratório, do enigmático, por oposição ao acessivel, do secreto, por oposição ao transparente. Naturalmente, esta demanda implica esforço moral e intelectual. As obras de arte autênticas serão consideradas trabalho duro, como frequentemente aconteceu no passado. Mas neste clima soporifero, o trabalho duro será considerado privilégio. Não apenas isso, estas obras têm de - só podem - infringir as leis da ordem soporifera. Talvez se tornem ilegais. Quem sabe? (p. 85).
}

\section{Referência bibliográfica}

BROWN, Mark (Ed.) (2011), Howard Barker Interviews 1980-2010: Conversations in Catastrophe, Bristol \& Chicago, Intellect, 214 pp. 